\title{
Inequalities in mortality in shrinking and growing areas
}

\author{
E Regidor, M E Calle, V Domínguez, P Navarro
}

J Epidemiol Community Health 2002;56:919-921

M odern societies are extremely mobile, yet the influence of population change in residential areas on mortality has rarely been investigated. Davey Smith et al showed that male and female mortality around the time of the 1991 census across 292 areas in Britain was inversely correlated with population growth in the previous two decades. ${ }^{12}$ Molarius and Janson studied 16 municipalities in Sweden and found a similar correlation between population changes from 1975 to 1994 and male mortality in 1992-96, but no correlation with mortality in women. ${ }^{3}$ The authors of both studies pointed out that, if possible, people leave unfavourable social and physical environments to move to more attractive places, so that relative population shrinkage occurs in areas with high mortality.

A subject that has not been investigated is the possible relation between population changes and the magnitude of inequalities in mortality. That is, does population change lead to decreasing or increasing mortality inequalities within areas? As a person's mobility is related with better health, ${ }^{4}$ inequalities in mortality are presumably smaller in growing areas than in those that are shrinking because people arriving in an area are healthy but their health is not dependent of their socioecenomic characteristics. ${ }^{56}$

\section{SUBJECTS, METHODS, AND RESULTS}

To test this hypothesis, we investigated the association between mortality inequalities in 1996-97 and population changes in the preceding decade in the Region of Madrid (Spain). For this purpose, we calculated the population change between 1986 and 1996 in 200 areas (179 municipalities and 21 districts of the city of Madrid). We then grouped these 200 areas into eight categories depending on the magnitude of the population change. We first identified the characteristics of each category in 1996-97 by the age standardised mortality ratio and different indicators of wealth and material deprivation; the magnitude of the mortality inequalities in each category was then calculated as the age adjusted relative mortality risk in persons with elementary or lower secondary education compared with those with upper secondary education or higher. The data to estimate mortality and inequalities in mortality in each area were obtained from the Mortality Study of the Region of Madrid. This study is based on information from the 1996 population census and on mortality data for 1996 and 1997 taken from the mortality registry. The two datasets were linked using personal characteristics that were common to both sets: name, date of birth, sex, and residential area. Linkage was achieved for $70 \%$ of all deceased persons and no significant variations in this percentage were found by sex, age group, or residential area. $^{7}$

In areas where the population has shrunk, mortality in men was higher than in those where the population has grown; in contrast, this did not occur in women (table 1). The correlation coefficient between the categories ranked by population change and the age standardised mortality ratio was -0.76 $(p=0.030)$ for men and $-0.13(p>0.05)$ for women. No relation was found between the eight categories ranked by population change and the indicators of wealth and material deprivation (table 1). These results show that the relation between male mortality and population change cannot be attributed to wealth or material deprivation in the area of residence. Both of the aforementioned studies also found that the relation between mortality and population change decreased only slightly or was unchanged after controlling for indicators of deprivation. ${ }^{13}$

Our study also found an association between population change and mortality inequalities in men: the correlation coefficient between the eight ranked categories and the magnitude of the relative mortality risk by educational level was $0.82(p=0.010)$. In women the correlation coefficient was 0.62 and was not statistically significant $(p=0.09)$. Nevertheless, after testing for equality of two correlations based on Fisher's Z transformation we cannot reject the null hypothesis that the correlation for men is equal to correlation for women. In both sexes, the mortality inequalities were greatest in the categories where the population was growing than in those where it was shrinking (table 2). Apart for accidents and accidental injuries in men, the results for the leading causes of death showed a similar pattern. So, although 95\% confidence intervals of the age adjusted relative mortality risks by educational level for growing and shrinking areas overlap, it would be not appropriate to interpret it as a sign of lack of difference between the two effect measures (table 2).

To determine why the findings with regard to mortality inequalities do not confirm our initial hypothesis, we looked at 1996-97 mortality in growing compared with shrinking areas by socioeconomic group. Mortality was 0.86 (0.83 to 0.89 ) times lower in growing than in shrinking areas for men belonging to the lower socioeconomic group and 0.76 ( 0.71 to 0.82 ) times lower for men belonging to the upper socioeconomic group. In women there were no differences in mortality in the lower socioeconomic group, but mortality in the upper socioeconomic group was 0.87 (0.77 to 0.97) times lower in growing than in shrinking areas. These results suggest that the greater mortality inequalities in growing areas could be attributable to a stronger health related selection bias in migration to these areas in the upper socioeconomic group (in the case of men), or that this selection bias could have been produced only in the upper socioeconomic group (in the case of women). Another, less plausible, explanation could be that persons in the upper socioeconomic group are more protected from the risk of dying by residing in growing areas than are persons in the lower socioeconomic group.

\section{COMMENT}

Although this is a cross sectional study, these results suggest that the variation in mortality inequalities between shrinking and growing areas could be attributable more to health selection bias in migration than to community characteristics. 
Table 1 Age standardised mortality ratio in 1996-97 and indicators of wellbeing and material poverty in 1996, by population change between 1986 and 1996

\begin{tabular}{|c|c|c|c|c|c|c|c|c|}
\hline \multirow{2}{*}{$\begin{array}{l}\text { Categories } \\
\text { of areas of } \\
\text { residence }\end{array}$} & \multirow{2}{*}{$\begin{array}{l}\text { Population } \\
\text { change (\%) } \\
\text { between } 1986 \\
\text { and } 1996\end{array}$} & \multirow{2}{*}{$\begin{array}{l}\text { Population } \\
\text { in 1996* }\end{array}$} & \multirow{2}{*}{$\begin{array}{l}\text { Deaths in } \\
1996-97^{*}\end{array}$} & \multicolumn{2}{|c|}{ Age standardised mortality rate ratio $(95 \% \mathrm{Cl})$} & \multirow{2}{*}{$\begin{array}{l}\text { Per capita } \\
\text { household } \\
\text { incomet in } \\
1996\end{array}$} & \multirow{2}{*}{$\begin{array}{l}\text { Percentage of } \\
\text { unemployment } \\
\text { in } 1996\end{array}$} & \multirow{2}{*}{$\begin{array}{l}\text { Percentage } \\
\text { of active } \\
\text { population in } \\
\text { class I in } 1996\end{array}$} \\
\hline & & & & Men & Women & & & \\
\hline 1 & $<-15$ & 297773 & 3453 & 100 & 100 & 1389.1 & 22.7 & 6.6 \\
\hline 2 & -15 to -10 & 559603 & 9184 & $104.6(99.1$ to 110.3$)$ & 91.5 (86.3 to 96.9$)$ & 1754.2 & 21.4 & 8.6 \\
\hline 3 & -10 to -5 & 609269 & 7661 & $95.2(90.1$ to 100.5$)$ & 93.4 (88.0 to 99.2$)$ & 1620.1 & 21.3 & 7.9 \\
\hline 4 & -5 to 0 & 334157 & 4085 & $97.1 \quad(91.3$ to 103.2$)$ & $92.6(86.6$ to 99.0$)$ & 1560.1 & 21.1 & 7.6 \\
\hline 5 & 0 to 10 & 608272 & 5087 & $89.9(84.8$ to 95.3$)$ & 92.4 (86.7 to 98.6$)$ & 1307.3 & 22.6 & 5.9 \\
\hline 6 & 10 to 20 & 543187 & 3645 & 86.1 (80.8 to 91.7 ) & 99.6 (92.9 to 106.8 ) & 1302.8 & 22.7 & 5.8 \\
\hline 7 & 20 to 40 & 485752 & 4413 & $97.6(92.0$ to 103.6$)$ & 93.1 (87.0 to 99.5$)$ & 1214.8 & 23.5 & 5.6 \\
\hline 8 & $>40$ & 424163 & 2842 & $76.2(71.2$ to 85.6$)$ & 94.5 (87.8 to 101.7 ) & 1612.4 & 19.0 & 10.7 \\
\hline
\end{tabular}

Likewise, the higher mortality observed in this study in shrinking areas-except for women in the lower socioeconomic group-, probably as a consequence of that health selection bias, would not support a policy of improving certain aspects of the local environment related with the quality of life in shrinking areas, as proposed by Davey Smith et al. ${ }^{2}$

In many highly mobile modern societies it is not easy to determine objectively whether areas of population growth are truly physically and socially attractive places to live. Rather, it may be that this belief is the product of a social consensus with no basis in fact, and that people migrate to these areas to live near to those whom they consider their economic and social peers. This has enormous ethical and political implications, as it is ethically debatable whether certain subjective components of quality of life, like the image and ambience of a place, notions of community or pace of life, should be subject to political intervention. It may be that the only politically reasonable and ethically acceptable interventions, both in shrinking and growing areas, are those that aim to modify the living conditions of those who are most socially deprived. But if healthier people move more to what are considered physically and socially atractive areas, the variation in mortality and the variation in mortality inequalities among residential areas with inverse population change is probably something that would be assumed as intrinsically associated with this move.

\begin{tabular}{|c|c|c|c|}
\hline \multirow{2}{*}{$\begin{array}{l}\text { Categories of areas of } \\
\text { residence }\end{array}$} & \multirow{2}{*}{$\begin{array}{l}\text { Population change } \\
\text { (\%) between } 1986 \\
\text { and } 1996\end{array}$} & \multicolumn{2}{|c|}{ Relative mortality risk $(95 \% \mathrm{Cl})^{*}$} \\
\hline & & Men & Women \\
\hline \multicolumn{4}{|l|}{ All causes } \\
\hline 1 & $<-15$ & 1.25 (1.11 to 1.41$)$ & 1.42 (1.14 to 1.79$)$ \\
\hline 2 & -15 to -10 & 1.37 (1.29 to 1.46$)$ & 1.28 (1.17 to 1.39$)$ \\
\hline 3 & -10 to -5 & 1.36 (1.27 to 1.46$)$ & 1.31 (1.18 to 1.46$)$ \\
\hline 4 & -5 to 0 & 1.38 (1.25 to 1.53$)$ & 1.18 (1.01 to 1.37 ) \\
\hline 5 & 0 to 10 & 1.32 (1.19 to 1.47$)$ & 1.21 (1.01 to 1.44$)$ \\
\hline 6 & 10 to 20 & 1.56 (1.36 to 1.79 ) & 1.50 (1.19 to 1.89 ) \\
\hline 7 & 20 to 40 & 1.61 (1.40 to 1.85$)$ & 1.85 (1.43 to 2.40$)$ \\
\hline 8 & $>40$ & 1.55 (1.36 to 1.76$)$ & 1.63 (1.34 to 1.98 ) \\
\hline $1+2+3+4$ & Decrease & 1.34 (1.29 to 1.39 ) & 1.29 (1.21 to 1.37$)$ \\
\hline $5+6+7+8$ & Increase & 1.51 (1.41 to 1.61$)$ & 1.49 (1.33 to 1.65 ) \\
\hline \multicolumn{4}{|l|}{ Specific causes of death } \\
\hline \multicolumn{4}{|l|}{ Cancer } \\
\hline $1+2+3+4$ & Decrease & 1.22 (1.14 to 1.31$)$ & 1.00 (0.90 to 1.10$)$ \\
\hline $5+6+7+8$ & Increase & 1.28 (1.15 to 1.42$)$ & 1.06 (0.89 to 1.25$)$ \\
\hline \multicolumn{4}{|l|}{ Lung cancer } \\
\hline $1+2+3+4$ & Decrease & 1.14 (1.00 to 1.29$)$ & $0.67(0.62$ to 1.98$)$ \\
\hline $5+6+7+8$ & Increase & 1.27 (1.05 to 1.55$)$ & $0.50(0.28$ to 0.85$)$ \\
\hline \multicolumn{4}{|l|}{ Cardiovascular diseases } \\
\hline $1+2+3+4$ & Decrease & 1.19 (1.11 to 1.28$)$ & 1.37 (1.23 to 1.52$)$ \\
\hline $5+6+7+8$ & Increase & 1.23 (1.09 to 1.38$)$ & 1.54 (1.24 to 1.91 ) \\
\hline \multicolumn{4}{|l|}{ Respiratory diseases } \\
\hline $1+2+3+4$ & Decrease & 1.44 (1.27 to 1.63$)$ & 1.39 (1.12 to 1.72 ) \\
\hline $5+6+7+8$ & Increase & 1.84 (1.45 to 2.32$)$ & 1.89 (1.18 to 3.03 ) \\
\hline \multicolumn{4}{|l|}{ Digestive diseases } \\
\hline $1+2+3+4$ & Decrease & 1.64 (1.39 to 1.94$)$ & 1.54 (1.20 to 1.98$)$ \\
\hline $5+6+7+8$ & Increase & 1.69 (1.30 to 2.19$)$ & 1.94 (1.16 to 3.25$)$ \\
\hline \multicolumn{4}{|c|}{ Accidents and accidental injuries } \\
\hline $1+2+3+4$ & Decrease & 1.46 (1.18 to 1.80$)$ & 1.18 (0.85 to 1.69$)$ \\
\hline $5+6+7+8$ & Increase & 1.33 (1.07 to 1.65$)$ & $1.51 \quad(0.96$ to 2.38$)$ \\
\hline \multicolumn{4}{|l|}{ Suicide } \\
\hline $1+2+3+4$ & Decrease & 1.74 (1.00 to 3.02 ) & 0.55 (0.17 to 1.73$)$ \\
\hline $5+6+7+8$ & Increase & 2.12 (1.26 to 3.56$)$ & 1.04 (0.38 to 2.82 ) \\
\hline
\end{tabular}




\section{Authors' affiliations}

E Regidor, M E Calle, V Domínguez, P Navarro, Department of Preventive Medicine and Public Health, Faculty of Medicine, Universidad Complutense de Madrid, Spain

Funding: this study was supported by a grant from the Consejería de Educación de la Comunidad de Madrid (no 06/0092/1999) and by a grant from the Fondo de Investigaciones Sanitarias (no 00/0514/1999).

\section{Conflicts of interest: none.}

Correspondence to: Dr E Regidor, Department of Preventive Medicine and Public Health, Faculty of Medicine, Universidad Complutense de Madrid, Ciudad Universitaria s/n, 28040 Madrid, Spain; enriqueregidor@hotmail.com

Accepted for publication 27 June 2002

\section{REFERENCES}

1 Davey Smith G, Shaw M, Dorling D. Shrinking areas and mortality Lancet 1998;352: 1439-30.

2 Davey Smith G, Shaw M, Dorling D. Population change and mortality in men and women. J Epidemiol Community Health 2001:55:9.

3 Molarius A, Janson S. Population change and mortality in men and women. J Epidemiol Community Health 2000;54:772.

4 Bentham G. Migration and morbidity: implications for geographic studies of disease. Soc Sci Med 1988;26:29-54.

5 Dunn JR, Dyck I. Social determinants of health in Canada's immigrant population: results from the National Population Health Survey. Soc Sci Med 2000;51:1573-93.

6 Singh GK, Siahpush M. All-cause and cause specific mortality of immigrants and native born in the United States. Am J Public Health 2001:91:392-9.

7 Regidor E, Guitiérrez-Fisac JL, Calle ME, et al. Infant mortality at time of birth and cause specific adult mortality among residents of the Region of Madrid born elsewhere in Spain. In J Epidemiol 2002;31:368-74.

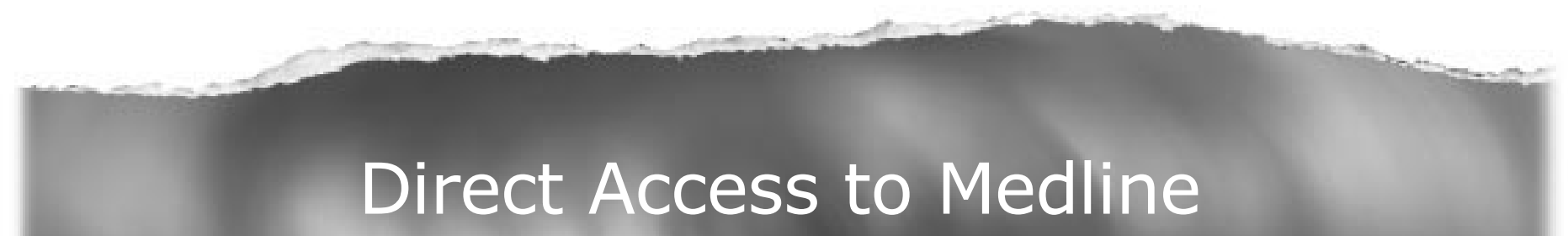

Medline

Link to Medline from the homepage and get straight into the National Library of Medicine's premier bibliographic database. Medline allows you to search across 9 million records of bibliographic citations and author abstracts from approximately 3,900 current biomedical journals.

\section{www.jech.com}

